\title{
Cooperation and Competition in Chimpanzees: Current Understanding and Future Challenges
}

\author{
JOHN C. MITANI
}

Two goals in the study of evolutionary anthropology are to determine the factors that make humans unique and to reconstruct the evolution of our behavior. As humans' closest living relatives, chimpanzees (Pan troglodytes) and bonobos (Pan paniscus) have always been of special interest in this regard. Because of their close evolutionary relationship to us, these animals provide the requisite comparative data to evaluate claims made about human uniqueness. In addition, knowledge of the differences among chimpanzees, bonobos, and us furnishes important insights into the changes that occurred during human evolution. Given these circumstances, studies of chimpanzees and bonobos remain high priorities for research. The volatile political situation in the Democratic Republic of the Congo, home to bonobos, has made long-term study of their behavior difficult, if not impossible. In contrast, field research on chimpanzees, initiated by Jane Goodall ${ }^{1}$ and Toshisada Nishida ${ }^{2}$ nearly 50 years ago, continues to grow and thrive. While past and ongoing field work has added enormously to our understanding of the behavior of chimpanzees, ${ }^{3-8}$ gaps in knowledge persist. In this paper, I summarize some of these gaps, giving special emphasis to male cooperation and female competition.

Cooperation and competition generate considerable theoretical interest and remain prominent issues in the study of evolutionary biology. Darwin's ${ }^{9,10}$ twin theories of natural selection and sexual selection furnish the

John C. Mitani is the James N. Spuhler Collegiate Professor of Anthropology at the University of Michigan. During the past 15 years, he has been engaged in a long-term study of the behavior of chimpanzees living in an unusually large community at Ngogo, Kibale National Park, Uganda. His research there focuses on male chimpanzee social behavior and cooperation. Over the past 30 years, he has conducted field work on all five of the living apes, including gibbons and orangutans in Indonesia, gorillas in Rwanda, bonobos in the Democratic Republic of Congo, and chimpanzees in Tanzania and Uganda. E-mail: mitani@ umich.edu)

Key words: chimpanzee; Pan troglodytes; behavior

C)2009 Wiley-Liss, Inc.

DOI 10.1002/evan.20229

Published online in Wiley InterScience (www. interscience.wiley.com). basis for our current understanding of cooperation and competition in the biological world. Cooperation, defined as behavior that increases the fitness of others, ${ }^{11}$ poses a problem because it is not immediately clear why organisms might help others in the face of selection operating to produce organic structures and behaviors "solely by and for the good of each." "Why males cooperate poses an additional puzzle because these individuals typically compete to fertilize females, who are neither easily divided nor shared. As a result, extensive research has been devoted to attempting to explain the evolution of cooperation during the past 50 years. ${ }^{11-20}$

After having been virtually ignored for 100 years after its publication in The Descent of Man and Selection in Relation to Sex, Darwin's theory of sexual selection now serves as the foundation for an active and vibrant field of research. Sexual selection furnishes a compelling rationale for why males frequently compete. A resurgence of interest in this evolutionary process during the past 40 years has led to the publication of several important studies regarding how males compete across the animal kingdom. ${ }^{21}$ The focus on male-male competition has tended to obscure the fact that females in a wide variety of species often compete. Growing realization of the importance of female competition, fueled in part by studies of primates, is beginning to alter this situation, leading to renewed attention to this process. ${ }^{22}$

My goal in the following is to provide a road map for future research. This road map depends, in part, on understanding what we already know. As a consequence, I highlight selected findings regarding male chimpanzee cooperation and female competition. This is not intended to be an exhaustive review of the literature, but instead an admittedly personal view of the state of the art and field. Because our current understanding of wild chimpanzee behavior derives from years of research by several individuals, it will be instructive to begin with a summary of the major long-term field studies of chimpanzee behavior.

\section{CHIMPANZEE FIELD STUDIES}

Much of our understanding of what it is to be a chimpanzee in the wild derives from the pioneering studies initiated by Jane Goodall ${ }^{23}$ at the Gombe National Park and Toshisada Nishida ${ }^{2}$ at the Mahale Mountains National Park, both in Tanzania. Field work by Goodall and her colleagues and Nishida and his co-workers now into their $49^{\text {th }}$ and $44^{\text {th }}$ years, respectively, has been responsible for seminal discoveries regarding chimpanzee tool use 


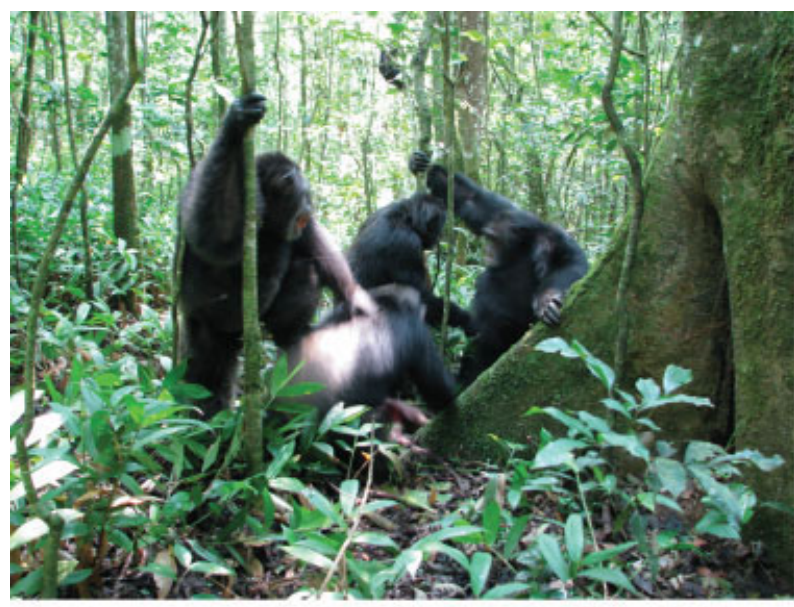

A

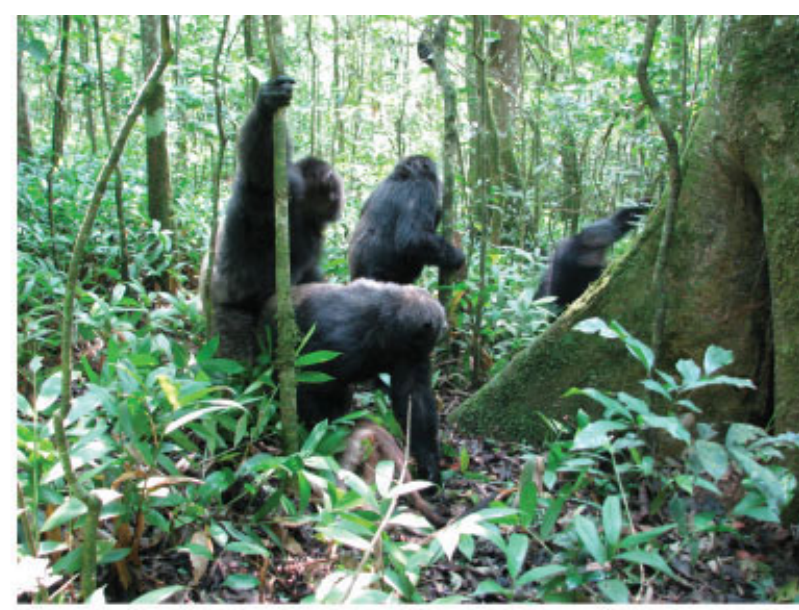

B

Figure 1. Male chimpanzee coalitionary behavior. A. The three males to the left have formed a coalition against the male on the right. B. The target of aggression in A. Is driven off by the combined efforts of the three males who have formed a coalition. (Color figure can be viewed in the online issue, which is available at www.interscience.wiley.com.)

and hunting, ${ }^{1}$ inter community violence and aggression, ${ }^{24,25}$ social structure and dispersal, ${ }^{2,26,27}$ culture, ${ }^{28}$ and medicinal plant use. ${ }^{29}$ Vernon Reynolds ${ }^{30}$ initially began field work on chimpanzees in the Budongo Forest Reserve, Uganda, at about the same time as Goodall and Nishida, in the early 1960s. Brief field studies by Yukimaru Sugiyama ${ }^{31}$ and Akira Suzuki ${ }^{32}$ preceded a long hiatus in research at Budongo as political unrest in Uganda made continuous work there impractical. In 1992, Reynolds reinitiated field work at Budongo, ${ }^{33}$ with research continuing to this day. ${ }^{34}$

Following Adrian Kortlandt's ${ }^{35}$ early field work at Bossou, Guinea, Sugiyama ${ }^{36}$ began intermittent observations there. Research at Bossou continues now under the direction of Tetsuro Matsuzawa. ${ }^{37}$ Woodland habitat characterizes Gombe and Mahale, while chimpanzees at Bossou live intermingled with humans. Recognizing the need for studies of chimpanzees in rainforests, Michael Ghiglieri ${ }^{38}$ initiated field work at Ngogo in the Kibale National Park, Uganda. Meanwhile, Christophe Boesch ${ }^{39}$ began long-term study in the Taï National Park, Ivory Coast. Ghiglieri's work spawned subsequent research on the Kanyawara community of chimpanzees in Kibale by Richard Wrangham and colleagues. ${ }^{40}$ Ghiglieri's and Wrangham's efforts also led to my own and David Watts's study of the Ngogo chimpanzees. ${ }^{41}$ Building on prior field work conducted by Bill McGrew and colleagues, $^{42}$ Jill Pruetz $^{43}$ has begun chimpanzee research anew in the region surrounding Mt. Assirik in Senegal. This study of chimpanzees living in a hot, dry, arid savanna complements another recently initiated field study of chimpanzees in the forests of the Republic of Congo, led by Crickette Sanz and Dave Morgan. ${ }^{44}$

In sum, previous and ongoing field research on chimpanzees has yielded over 200 person years of observations and resulted in an unprecedented amount of data. These data lay the groundwork for studies investigating the dual problems of male cooperation and female competition.

\section{MALE CHIMPANZEE COOPERATION}

Male chimpanzees are extremely gregarious $^{2,3,40,45-47}$ and frequently engage in highly charged, noisy aggressive interactions. This led early observers to emphasize the role that male competition plays in chimpanzee life. ${ }^{48,49}$ High levels of male competition follow directly from the low reproductive rates of female chimpanzees, which give birth once, on average, every 5-6 years. ${ }^{3,5,6,50}$ Heavily biased male operational sex ratios result, with the number of reproductively active males dwarfing the number of reproductively active females at any moment in time. This sets the stage for intense male-male competition for mates and reproductive opportunities.

Male chimpanzees compete within and between communities. Within communities, male chimpanzees strive for status as they attempt to dominate others, forming linear dominance hierarchies in the process. ${ }^{46,51-53}$ Recent research from several sites now indicates that males achieving high dominance rank obtain substantial fitness benefits, with alpha males siring up to $30 \%-50 \%$ of all infants born during their tenures at the top of hierarchies. ${ }^{53-56}$ Male chimpanzees also compete with conspecifics from other communities as they defend their feeding grounds via group territorial behavior. $^{57}$

Despite their highly competitive nature, male chimpanzees also cooperate in several contexts to obtain direct and indirect fitness benefits. ${ }^{7,58}$ Coalitionary behavior, meat sharing, and territorial boundary patrolling provide three examples in this regard.

\section{Coalitionary Behavior}

Coalitions are a conspicuous and theoretically interesting aspect of primate behavior, taking place in species across the Order. ${ }^{59}$ Coalitionary behavior involves two or more individuals cooperating to direct aggression toward others (Fig. 1). In these situations, one animal typically intervenes in an ongoing dispute between two 
individuals. That primates form coalitions so readily raises a puzzling evolutionary question. Why does a third party come to the aid of another and put him or herself at risk in the process?

Previous studies of male chimpanzees have emphasized the crucial role coalitions play in the acquisition of dominance rank. Because high rank confers fitness benefits, ${ }^{53-56}$ males compete vigorously to achieve alpha status. While large, strong males occasionally rise to the top, coalitionary support is frequently a more critical variable in that males typically obtain the alpha position only if they receive help from others. ${ }^{60-65}$ Seminal studies of chimpanzees in captivity by DeWaal $^{61}$ and in the wild by Nishida ${ }^{62}$ document the complex coalitionary tactics male chimpanzees employ as they cooperate to overthrow alpha males. In these situations, male chimpanzees form coalitions to improve their own status and are likely to benefit directly. Additional observations suggest that male chimpanzees reciprocally exchange support and engage in more complex interactions, trading coalitionary support for goods and services such as grooming and meat. ${ }^{66-68}$ Other studies indicate that alpha males cede matings to lower ranking males, who help them maintain their position in the dominance hierarchy. ${ }^{62,69}$ All of these studies invoke reciprocity and continue to be debated, as the importance of this process in animals other than humans is unclear. $^{17,70}$ In research on wild chimpanzees, it is extremely difficult to establish the contingent nature of exchanges between individuals who live in uncontrolled conditions and who are not always together due to the fission-fusion nature of their society. More work, perhaps in captivity, where the behavior of one individual can be shown to depend on the actions of another, will be necessary to address this concern. ${ }^{71}$

The previous examples suggest that males receive direct fitness benefits through coalitionary behavior. In recent work, my colleagues and I have investigated whether male chimpanzees derive indirect benefits by forming coalitions with others. Here we combined genetic analyses designed to determine who is related to whom with long-term behavioral observations to ask whether genetic relationships affect who does what with whom. Our results indicated that maternal half siblings form coalitions more often than do unrelated or distantly related individuals. ${ }^{58}$ In contrast, rates of coalition formation did not differ between paternal half siblings and nonkin. Finally, several pairs of males supported each other more often than predicted by chance, and most of these dyads were unrelated. ${ }^{58}$ Taken together, these results suggest that male chimpanzees form coalitions primarily for selfish reasons, obtaining direct fitness benefits as they do so.

Prior research reveals how male chimpanzees use coalitions to improve their own fitness and those of their close relatives, thereby helping to

\section{That primates form coalitions so readily raises a puzzling evolutionary question. Why does a third party come to the aid of another and put him or herself at risk in the process?}

resolve the apparent paradox posed by individuals who support others. Nevertheless, several unanswered questions remain regarding male chimpanzee coalitionary behavior. Specifically, we know remarkably little about the frequency, form, and long-term function of coalitionary behavior. While it is sometimes claimed that male chimpanzees form coalitions often, ${ }^{72,73}$ scant data exist to evaluate exactly how often they do compared with other primate species. ${ }^{74,75}$

Additional data regarding the natural history of male chimpanzee coalitionary behavior are sorely lacking. Coalitions are heterogeneous in form, involving a minimum of three individuals. In situations where two individuals are involved in an aggressive interaction and a third party intervenes, the latter ("supporter") helps one of the two contestants ("recipient") targeting the third individual ("target"). In "conservative" coalitions, ${ }^{72}$ two high-ranking individuals cooperate to attack a lower ranking animal (Fig. 2). Alternatively, a high-ranking individual can join forces with a low-ranking individual in a "bridging" coalition to direct aggression toward an animal ranking between them both (Fig. 2). A third possibility involves "revolutionary" coalitions in which two low-ranking animals cooperate against a higher ranking individual (Fig. 2).

Different types of coalitions are likely to have different ultimate effects. A great deal has been written about how male chimpanzees form revolutionary coalitions as they attempt to improve their own status, causing dramatic upheavals in the dominance hierarchy in the process. $^{61-63}$ Less attention has been paid to conservative and bridging coalitions. The former reinforce the status quo, with two males benefiting by stabilizing and maintaining their positions in the dominance hierarchy. Participants derive similar direct fitness effects through bridging coalitions. In one type of bridging coalition (top panel, Fig. 2), a low-ranking male might support one high-ranking individual against another high-ranking individual to gain leverage against the latter. In a second type of bridging coalition (bottom panel, Fig. 2), a high-ranking animal might support the lower ranking individual of a pair to reinforce his relative position in the hierarchy.

Revolutionary coalitions have received considerable research attention, in part because of the significant effect they have on male dominance relations and thus male fitness. This has led to a general impression that revolutionary coalitions form quite frequently, but this is unlikely to be the case as male chimpanzee dominance hierarchies are often stable for long periods, with alphas remaining unchallenged as a result. At Ngogo, two males maintained their alpha status for more than seven years, during which time their position at the top was only rarely threatened in serious fashion. In sum, quantitative data are necessary to evaluate how often different types of coali- 


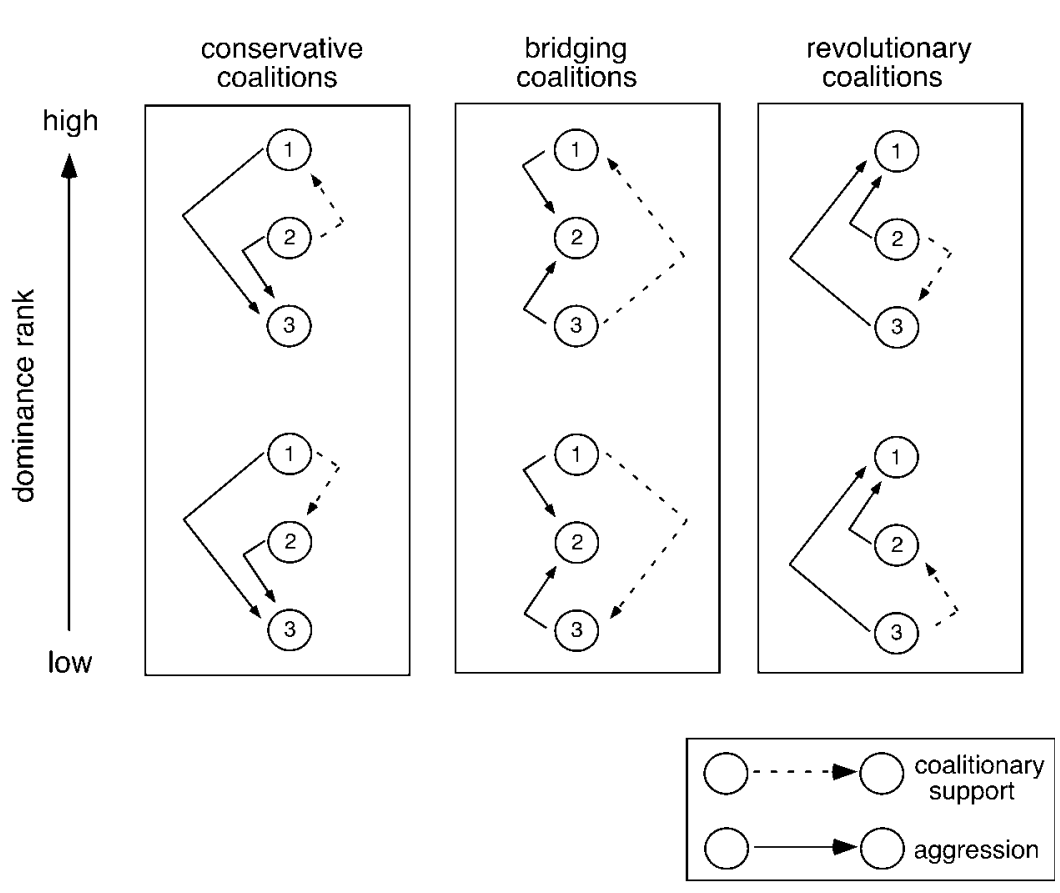

Figure 2. Types of coalitionary behavior. Solid arrows indicate directions of coalitionary aggression toward third-party targets. Broken arrows show who supports whom.

tions actually occur and to assess their concomitant fitness effects.

Several outstanding questions remain regarding the frequency, form, and function of short-term coalitions. However, the development and longterm maintenance of coalitions also warrant further study. My own anecdotal observations suggest that males may not always help their younger maternal brothers when there is a large disparity in age, with strong cooperative bonds forming between them only when both are adults and in a position to obtain reproductive benefits by aiding each other. Additional observations also suggest that males may begin to support their younger brothers more vigorously as they age. In these situations, males may increase their help to others as their own reproductive value declines. Additional long-term study will be necessary to evaluate these possibilities.

Animals that consistently support each other over long periods are said to form an "alliance." is needed to describe how short-term coalitions between specific pairs of males develop into long-term alliances. What factors affect the development of alliances and their long-term stability? Recent studies of female monkeys indi- cate that individuals who form strong social bonds reproduce more than do females who develop only weak bonds. ${ }^{77,78}$ Because reproduction is the currency of import in the eyes of evolution, an important goal for future research will be to document the longterm fitness consequences of male chimpanzee coalitionary behavior. Recent research indicates that male chimpanzees form long-lasting and enduring social bonds with others, ${ }^{79}$ but to what extent do these bonds, manifested by participation in coalitions, affect male reproduction? Finally, we know little about the cognitive mechanisms and communicative processes that underlie chimpanzee coalitionary behavior. Field observations and experiments previously employed to investigate cognition and communication in monkeys will be required to address these issues. ${ }^{80,81}$

\section{Meat Sharing}

The hunting behavior of chimpanzees has been studied intensively at several study sites. ${ }^{82-90}$ The favored prey of chimpanzees are red colobus monkeys, which they hunt avidly wherever the two species live sympatrically. Chimpanzees also hunt other vertebrate prey in habitats where red colobus monkeys do not exist. ${ }^{43,91-93}$

Chimpanzees frequently share meat that they obtain in hunts (Fig. 3). ${ }^{66,84,94-96}$ At first glance, meat sharing is one of the most perplexing facets of chimpanzee behavior. Meat, after all, is an extremely valuable resource, packed with valuable micronutrients that are not easily obtained elsewhere, ${ }^{41,97}$ making it highly prized by all individuals. Most chimpanzees, however, consume meat infrequently because it is extremely hard to obtain. At Taï and Ngogo, chimpanzees engage in prolonged "hunting patrols" during which chimpanzees travel in an apparently purposive fashion across their territories in search of red colobus prey. ${ }^{84,87}$ Hunting patrols are energetically costly as patrollers rarely feed while they search for monkeys over periods averaging two hours. Patrols can sometimes last five to six hours of a 12-hour day. Chimpanzees may hunt red colobus monkeys upon encounter, but hunts themselves are potentially costly, as adult male colobus monkeys typically mob and wound chimpanzee predators. Taken together, the inherent costs associated with hunting make it puzzling why chimpanzees share meat with others.

Prior research has highlighted a potential intersexual function of meat sharing. Building on a proposal initially made by Geza Teleki, ${ }^{82}$ who conducted the first systematic study of the hunting behavior of wild chimpanzees at Gombe, Craig Stanford and colleagues $^{94}$ hypothesized that male chimpanzees are motivated to hunt to obtain meat that they use to swap for matings. A similar hypothesis has recently been proposed to explain food sharing between male and female chimpanzees. ${ }^{98}$ Despite the provocative nature of these hypotheses, several observations have been made that are not consistent with them. Estrous females do not always obtain meat from their begging efforts and matings do not regularly occur when males share meat with females. ${ }^{66,95}$ Additional data indicate that male chimpanzees do not always hunt red colobus monkeys upon encountering them and that the presence of estrous females actually inhibits hunting attempts by males. ${ }^{66,97}$ In situations where male chimpanzees pursue mon- 


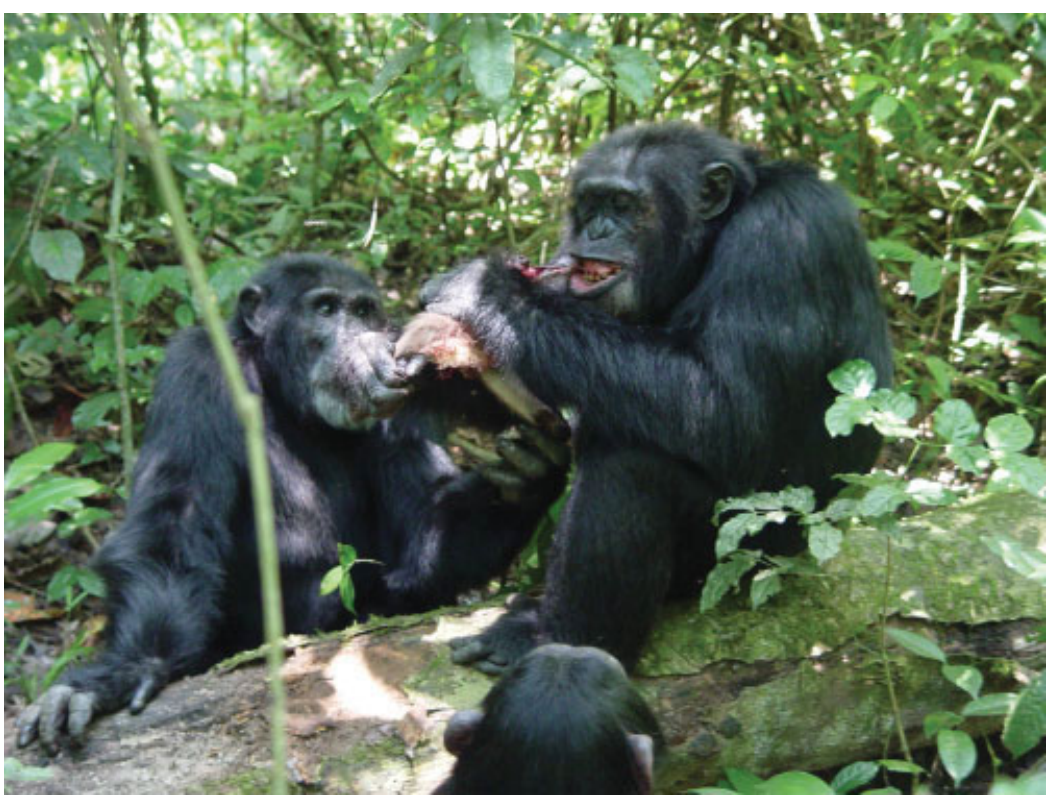

Figure 3. Male chimpanzee meat-sharing behavior. The male chimpanzee on the right tears off of a piece of meat, which he will later share with the male on the left. (Color figure can be viewed in the online issue, which is available at www.interscience.wiley.com.)

keys instead of guarding estrous females, males are likely to suffer opportunity costs in the form of lost matings. ${ }^{97}$ Finally, sharing meat with females fails to improve male mating success. ${ }^{66}$

While the preceding findings do not support the hypothesis that male chimpanzees share meat with females to improve their mating success, a recent study from the Taï National Park suggests otherwise. ${ }^{96}$ Observations made there indicate that males copulated more frequently if they shared meat with females than if they did not. This relationship persists after controlling several potential confounding variables, including male dominance rank, the amount of time males and females spent together, and female age, gregariousness, and frequency of begging. The discrepancy between these results and those derived from other research may be due to two different reasons, both of which require further investigation. First, the reported differences may be attributable to differences in the length of study. While the report from Taï was based on data collected over 22 months, previous research examined the relationship between male meat sharing and mating success over shorter times. Second, published dif- as male chimpanzees at Ngogo share meat nonrandomly and reciprocally with each other and exchange meat for coalitionary support. ${ }^{66}$ More recent studies at Gombe suggest that male chimpanzees there do not use meat as a social tool in a similar way. ${ }^{95,97}$ This claim is difficult to evaluate as the critical data needed to test this hypothesis have not been presented. Specifically, it remains to be determined whether males at Gombe or at any other site exchange meat for coalitionary support. In sum, further study will be necessary to assess how generally we can apply the male social bonding hypothesis across chimpanzee communities.

Recently, a third hypothesis has been revived to explain the meat-sharing behavior of chimpanzees. Extending an idea originally proposed by Richard Wrangham, ${ }^{102}$ Ian Gilby ${ }^{95}$ has proposed that chimpanzees share meat to reduce the costs associated with possession. This "sharing under pressure" hypothesis begins with the observation that hunts generate considerable frenzy. Because meat is a scarce and valuable resource, several chimpanzees typically gather around individuals who have captured prey, harassing them and attempting to grab bits of meat. This hypothesis proposes that meat sharing represents a form of "tolerated theft"103 and that possessors share meat primarily to reduce the costs of harassment imposed by beggars. Observations at Gombe support this hypothesis. Feeding rates by individuals who possess meat decrease as a function of the number of beggars, the probability of sharing increases with the occurrence and duration of harassment, and levels of harassment decline following sharing events. ${ }^{95} \mathrm{De}-$ spite these findings, the hypothesis fails to explain why alpha males, who frequently possess meat and are not especially vulnerable to harassment, readily share with others. In addition, the hypothesis does not account for voluntary transfers that are frequently made by other chimpanzees. In sum, the sharing-under-pressure hypothesis goes some way to explain why chimpanzees share meat. It may, in fact, may be more broadly applicable to the behavior of chimpanzees at other study sites. To date, however, the necessary data to test this hypothesis elsewhere have not 
been collected. Consequently, as is the case with the male social-bonding hypothesis, it is unclear to what extent the sharing-under-pressure hypothesis applies to the meat-sharing behavior displayed by chimpanzees in other communities. Additional work will be required to address this issue.

Ideally, future studies will continue to consider the possibility that meat sharing occurs for different reasons, as the male social bonding and sharing under pressure hypotheses are not mutually exclusive. In this regard, anecdotal observations made at Ngogo suggest that meat may be relinquished or stolen shortly after initial capture, but is treated with remarkable "respect for ownership" thereafter, leading to voluntary exchanges between individuals. In addition, it will repay the effort to revisit how we define and operationalize terms. For instance, Gilby ${ }^{95}$ defines chimpanzees who "harass" individuals who possess meat as those who sit next to them, reach without touching them, hold the carcass of the prey, and touch the possessor's mouth. Most of these behaviors do not accord with what would commonly be considered harassment. It will be important, therefore, to standardize definitions so that they are operationally tractable and yield results that can be compared in meaningful ways across studies. Because chimpanzees are well known for displaying intraspecific variation in behavior, ${ }^{104,105}$ it will also be important to consider the possibility that the reported differences in meat sharing reflect real differences in the behavior of chimpanzees across study sites. In sum, the meat sharing behavior of chimpanzees continues to generate new questions. Equally compelling questions about male chimpanzee cooperation emerge from observations of their territorial behavior.

\section{Territorial Boundary Patrols}

Perhaps the most dramatic way that male chimpanzees cooperate is in their territorial behavior. Chimpanzees are typically hostile to members of other communities. Intercommunity aggression occasionally leads to fatalities as male chimpanzees make lethal coalitionary attacks on their neighbors (Fig. 4). ${ }^{24,106-111}$ Adult male chimpan- zees are typically targeted in such attacks, with most fatalities involving them. ${ }^{7,112}$ However, infants also frequently fall victim, with the killers cannibalizing them in the process. ${ }^{7,112}$ Current evidence suggests that by killing conspecifics in other communities male chimpanzees achieve dominance over their neighbors and are thus able to expand their territories at the latters' expense. Territorial expansion, in turn, leads to larger feeding territories and improved reproduction by community females. ${ }^{57}$ These observations leave three questions unanswered. First, females are rarely recruited into new communities because secondary trans-

\section{... the sharing-under- pressure hypothesis goes some way to explain why chimpanzees share meat. It may, in fact, may be more broadly applicable to the behavior of chimpanzees at other study sites. To date, however, the necessary data to test this hypothesis elsewhere have not been collected.}

fer does not typically occur. Thus, why are females from other communities seldom targeted and killed? Second, why are infants typically cannibalized? Alternatively, why are adult chimpanzees left unconsumed? To date, these questions remain unresolved.

Attacks on chimpanzees belonging to other communities are frequently preceded by territorial boundary patrols, a behavior that raises additional questions about male cooperation (Fig. 5). Patrols typically involve males, who move together in single file and directed fashion to the periphery of their territory. When they arrive, their behavior changes dramatically. Patrollers fall completely silent. They visually scan the environment, sniff the ground, and check signs, such as urine, feces, and food, left behind by conspecifics. Occasionally, patrollers make deep incursions into the territories of their neighbors. At Ngogo, patrols include, on average, about 13-18 individuals and occur about once every 9-10 days. ${ }^{106,113,114}$ Patrollers make aural or visual contact with members of adjacent communities in about $30 \%$ of these events. ${ }^{106}$

Patrols are costly. Individuals who participate can, at least in theory, be attacked by members of other communities and injured or killed in the process. Patrollers also incur energetic and opportunity costs. Patrols at Ngogo last an average of two hours, during which chimpanzees feed less and travel more than they do during other times. ${ }^{114}$ Whether the psychological stress and energetic costs associated with patrols have a measurable physiological effect on participants remains to be determined. Tangible costs nevertheless exist, and patrollers can offset these costs by obtaining several benefits through the joint defense of territories. These benefits include increased access to food and improved safety. Because these benefits are likely to be shared, males are predicted to contribute regularly and participate in patrols with equal frequency. Our observations nevertheless indicate that there is considerable heterogeneity in patrol participation. ${ }^{106}$ While some males patrol quite often, others participate infrequently (Fig. 6). Data such as these create a classic cooperation problem. Specifically, why are some males permitted to "free-ride" and to refrain from participating, thus reaping the communal benefits derived from territorial patrols without paying any of the costs?

Several possibilities exist, all of which require further study. First, heterogeneity in participation may reflect the fact that the fitness benefits of patrolling are not equally distributed among males. As a result, some males may be willing to pay greater costs than others, with the former participating more frequently than the latter. In this regard, previous observations at Ngogo reveal that male patrolling effort varies positively with mating success. ${ }^{106}$ From this, it is tempting to conclude that males who mate frequently, and presumably have the 

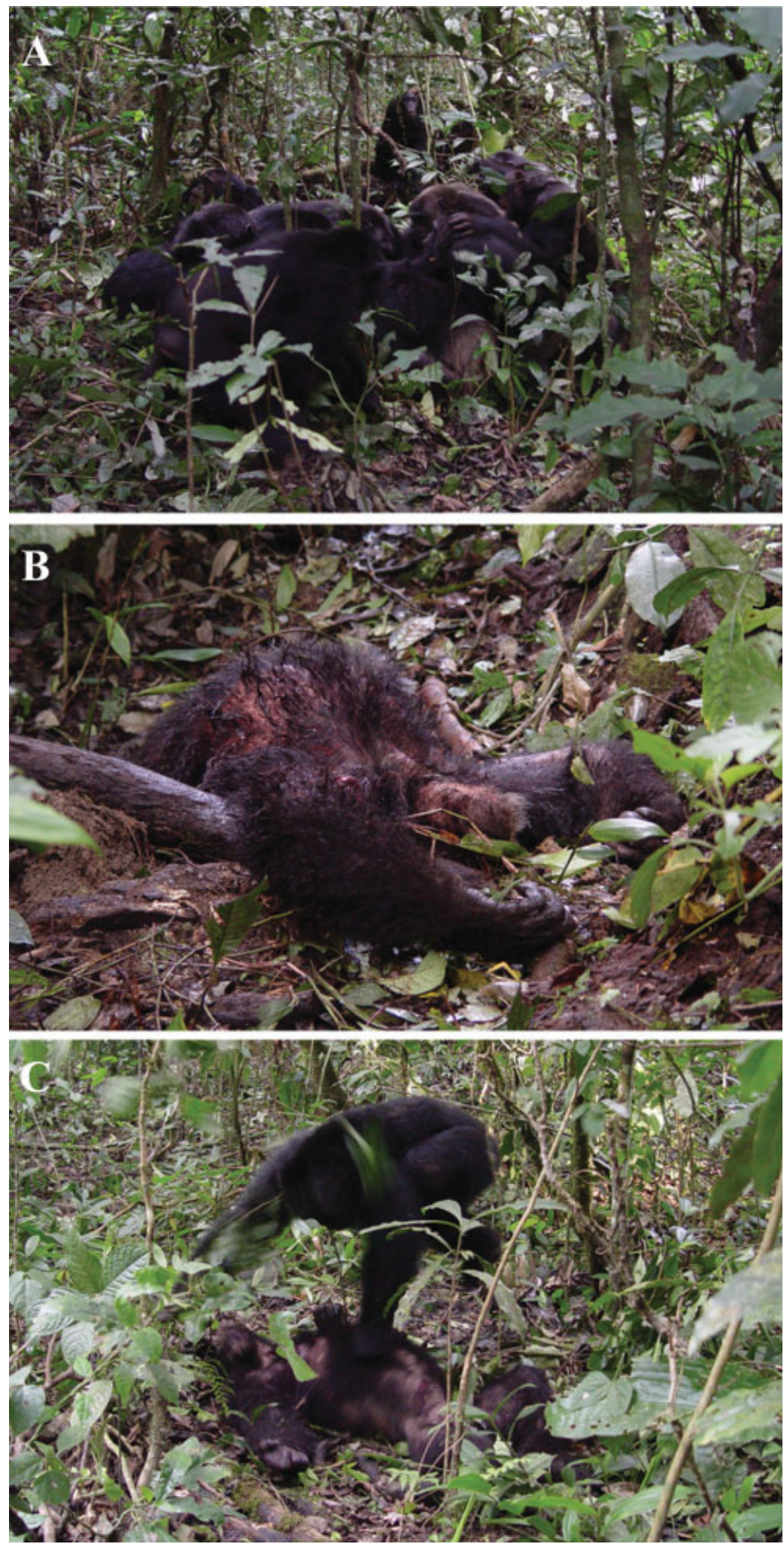

Figure 4. Lethal coalitionary aggression. A. A group of male chimpanzees attack an adult male from another community. The victim is at the bottom of the pile of attackers and hidden from view. B. After 15 minutes, the victim is dead. C. About 40 minutes later, a young adult male who participated in the attack leaps on the dead body of the victim. (Color figure can be viewed in the online issue, which is available at www.interscience.wiley.com.) most offspring in the group to protect now and in the future, are motivated to patrol more than are males who mate less often. Ultimately, our ability to assess whether males accrue variable fitness benefits by patrolling will depend on establishing a direct link between male reproduction and patrolling frequency. Long-term records of males that do and don't patrol, combined with paternity analyses using genetic markers, can be employed to investigate this possibility.

Male chimpanzees may obtain other direct benefits by participating in patrols. Because patrols are costly in terms of time and energy, and can potentially lead to injury during aggressive encounters with neighbors, they provide a forum for males to advertise their ability and willingness to take risks, and thus their quality as potential long-term allies. To date, the hypothesis that patrolling represents a form of costly signaling ${ }^{115,116}$ has received scant attention. A direct test of the hypothesis will require additional observations regarding whether variation in patrol participation affects rates of received aggression and alliance formation.

Male chimpanzees are philopatric, ${ }^{26,27}$ and thus live with their genetic relatives throughout their lives. From this, a third possibility arises, which is that males adjust their patrolling effort to obtain indirect fitness benefits. ${ }^{117}$ Specifically, this hypothesis predicts that variation in the number of close kin with whom a male co-resides will affect his tendency to patrol, with males having many kin expected to patrol more often than do individuals having fewer relatives to protect.

Finally, fitness costs, as well as benefits, might affect variation in patrol participation, leading to a fourth hypothesis, that males punish others who fail to patrol. Punishment, defined as "retailiatory infliction of fitness reduction,"118 can prevent others from engaging in harmful behaviors as well as encourage them to perform beneficial behaviors. Compared with other potential explanations for cooperative behavior, punishment has received relatively little attention in studies of animal behavior. Observations of captive chimpanzees indicate that males attack their long-term allies who fail to 


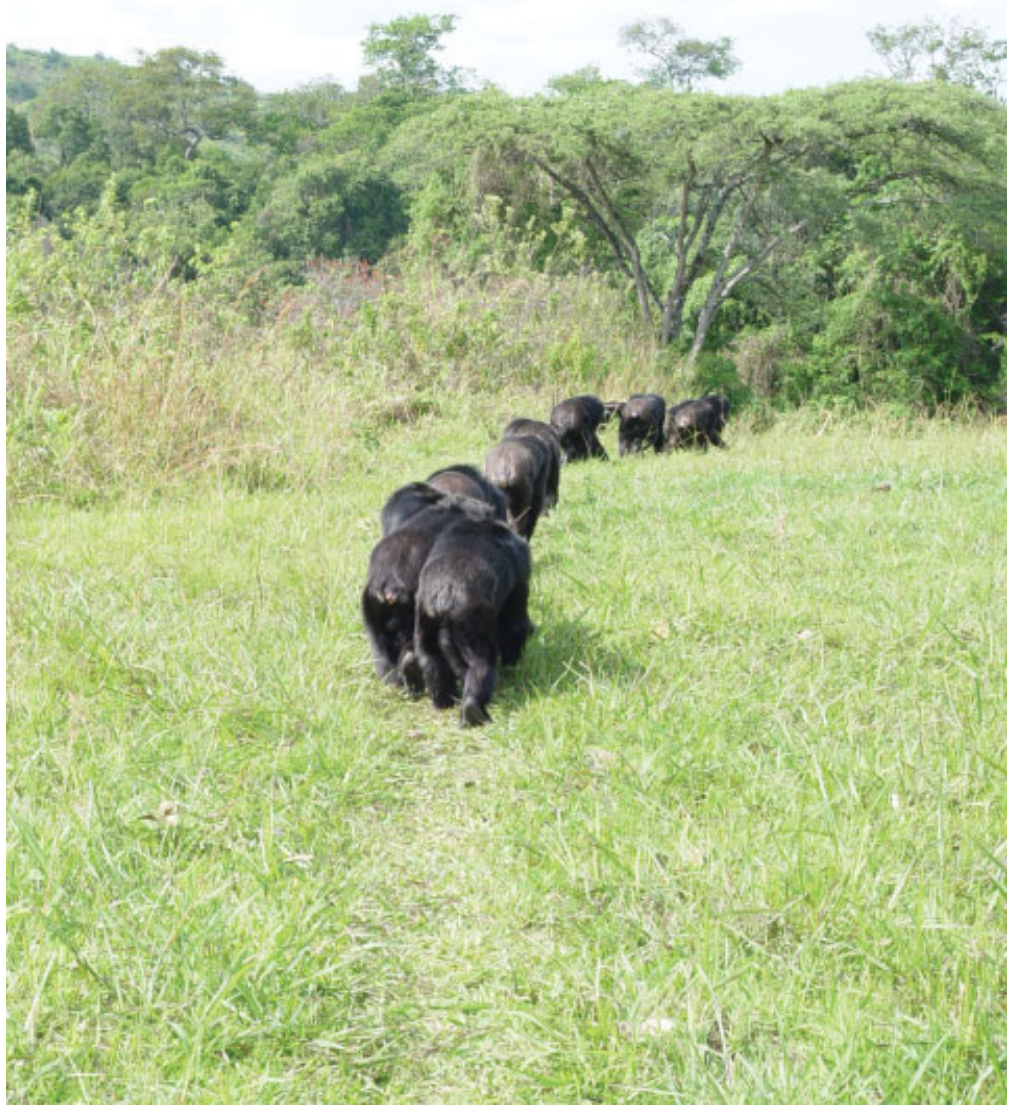

Figure 5. Territorial boundary patrol. Male chimpanzees patrol their territories by moving in single file, occasionally making deep incursions into neighboring territories. (Color figure can be viewed in the online issue, which is available at www.interscience. wiley.com.)

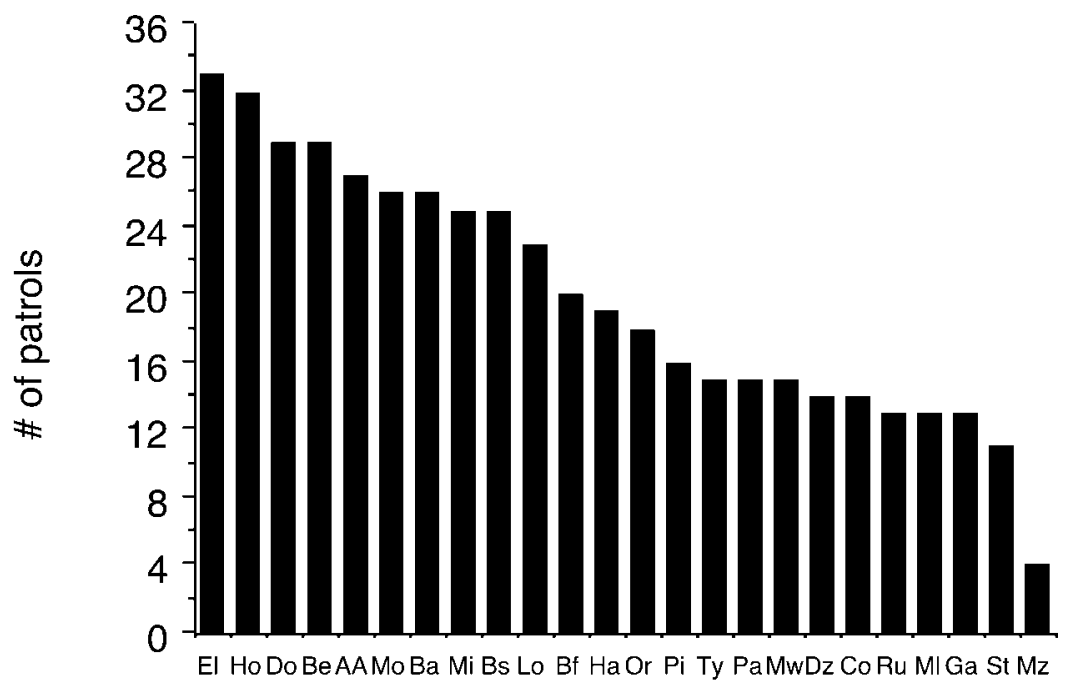

male

Figure 6. Inter-individual variation in the tendency to patrol. Data from Watts and Mitani. ${ }^{106}$ provide coalitionary support, ${ }^{61}$ but whether groups of males punish others who do not participate in boundary patrols remains an open question in need of further study.

\section{FEMALE CHIMPANZEE COMPETITION}

Our knowledge of the behavior of female chimpanzees lags behind studies of male behavior and remains far from complete. There are several reasons for this, which are unrelated to any lack of interest or field effort on the part of researchers. Put simply, female chimpanzees are very difficult to study. Female chimpanzees, specifically those living in East Africa, are relatively asocial. ${ }^{119-122}$ Because of this, females rarely interact with conspecifics, so that social relationships between them have been difficult to document. In addition, females reproduce slowly ${ }^{3,5,6,50}$ and most disperse from their natal groups, 5,26,27 making their subsequent activities invisible to human observers. Given these circumstances, it has taken an extraordinary amount of time to obtain even the most basic information about the behavior of female chimpanzees in the wild.

Social relationships between females represent one aspect of behavior that has proven hard to unravel. In striking contrast to males, female chimpanzees show few overt signs of striving for status. This, combined with their comparatively low rates of interaction, makes it notoriously difficult to rank females. Dominance rank relationships between individuals can, on occasion, be determined, but typically only after many years of observation. ${ }^{123-128}$ As a result, female chimpanzees are often portrayed as comparatively shy, secretive, and noncompetitive. Long-term studies are beginning to transform this depiction of female chimpanzees, revealing a surprisingly competitive side that has remained hidden until now.

Female chimpanzees display extremely slow life histories, characterized by prolonged development, delayed reproduction, and low reproductive rates. ${ }^{3,5,6,50}$ These factors lead to the natural expectation that females 
will compete, but for what? Here sexual selection theory provides critical insight. Female chimpanzees, like most other mammals, invest more in their offspring than do males. As a consequence, their reproduction is typically limited by the ability to convert environmental energy directly into offspring, with the result that females compete primarily for food. ${ }^{129}$ Because chimpanzees specialize in feeding on ripe fruit, ${ }^{130}$ they face a limited and unpredictable food supply that fluctuates in space and time. This foraging regime creates a special challenge for females. Those living in East Africa appear to adapt by moving alone with their dependent offspring over relatively small core areas within the larger territory occupied by the entire community. ${ }^{121,122,126,131}$ Following dispersal, females settle into core areas and remain faithful to them over time. Through long-term site fidelity to core areas, females presumably become intimately familiar with the locations of food in good times and bad. Recent observations now reveal that instead of competing directly for food during face-to-face encounters with conspecifics, female chimpanzees compete for high-quality core areas. $^{125,126,128}$

The tropical habitats occupied by chimpanzees are heterogeneous and, as a consequence, female core areas vary in quality and size. Studies of East African chimpanzees indicate that high-ranking females reside in more productive core areas than do lowranking individuals. Specifically, the core areas of dominant females are smaller and contain more preferred foods than do those occupied by subordinates. ${ }^{126,128}$ Despite long-term site fidelity, the core areas of individual females change in size over time as a function of feeding competition. During periods of fruit scarcity, competition for food is accentuated, and at Gombe, differences in the size of core areas occupied by high- and low-ranking females grow larger. ${ }^{126}$ Observations of interactions between immigrant and resident females have provided further evidence of female competition. When new females immigrate into communities and attempt to establish core areas, they meet sharp resistance from residents, with rates of aggression increasing between them. ${ }^{128,132}$ While attempting to settle, immigrant females increase their rates of association with males who, in turn, protect them from attacks. In this way, immigrants are able reduce the levels of aggression they receive from resident females. ${ }^{127}$

Taken together, the preceding observations suggest that female chimpanzees compete for space, with highranking females excluding lower ranking females from high-quality habitats. This, in turn, has important consequences for female feeding behavior, condition, and reproduction. Highranking females, who inhabit highquality core areas, spend less time for-

\section{Put simply, female chimpanzees are very difficult to study. Female chimpanzees, specifically those living in East Africa, are relatively asocial. Because of this, females rarely interact with conspecifics, so that social relationships between them have been difficult to document.}

aging and eat higher quality foods than do low-ranking females. ${ }^{125,133}$ Dominant females are also heavier and show less variation in weight across seasons than do subordinate females. ${ }^{134}$ Moreover, the attendant feeding advantages obtained by competition for space and food influence female reproduction in important ways. At Gombe, high-ranking females live longer and have shorter birth intervals than do lowranking females. ${ }^{135}$ Dominant females also give birth to more surviving offspring and produce daughters that reach sexual maturity earlier than do those born to subordinate mothers. ${ }^{135}$ Similar observations have recently been reported at Kanyawara, where female chimpanzees who occupy core areas with more preferred foods have shorter birth intervals and higher infant survivorship than do those living in poorer habitats. ${ }^{133}$

Recent studies are beginning to reveal that female chimpanzees compete with each other for space, food, and opportunities to reproduce. Female competition, for the most part, is indirect and manifest in subtle ways, differing dramatically from the loud, conspicuous, aggressive interactions that frequently take place between male chimpanzees. Additional observations indicate, however, that competition between female chimpanzees can escalate significantly under certain circumstances. Competition between female chimpanzees is particularly acute when new females immigrate into communities. As they attempt to integrate themselves into their new homes and establish a core area, immigrant females receive considerable aggression from resident females. At Gombe and the Budongo Forest Reserve, resident females have now been observed to form coalitions to attack and kill the infants of immigrant females. ${ }^{34,132}$ These attacks are particularly extreme manifestations of competition between female chimpanzees for space and food.

The research summarized here has begun to paint an unexpectedly complex picture of female chimpanzee behavior. But much remains to be learned. Specifically, what are the physiological causes and consequences of female competition? How do immigrant females integrate themselves into their new communities? How do immigrants select their core areas? What factors influence their decisions? How does female competition influence the short- and long-term strategies mothers use in raising their young? Studies of primates, which are longlived and reproduce slowly, have yielded scant data about infant growth and development. As a result, we continue to lack information about how maternal behavior influences patterns of chimpanzee development in the wild. Long-term behavioral observations combined with endocrine analyses of samples noninvasively collected from animals in the wild will provide a way to address these and other questions 
about the behavior of female chimpanzees. As studies continue to highlight intraspecific variation in chimpanzee behavior, ${ }^{104,105}$ it will be important to examine whether, how, and why patterns of female competition vary across populations. For example, it has become increasingly clear that female chimpanzees living in the Taï National Park in West Africa are much more social than are individuals in East Africa. ${ }^{136}$ Collaborative work implementing standardized methods of data collection and analysis is needed to validate these differences and to investigate their causal, developmental, and functional correlates.

\section{IMPLICATIONS FOR HUMAN BEHAVIOR AND EVOLUTION}

Evolutionary anthropologists take a keen interest in studies of chimpanzees and bonobos because they are our closest living relatives. As such, they provide valuable information to assess how we as a species are unique and to reconstruct the evolution of human behavior. Differences that exist among all three species highlight changes that have occurred during the course of human evolution and some of the selective factors that contributed to our extraordinary spread and dominance on earth. For example, the research reviewed here indicates that male chimpanzees cooperate in several situations, including coalitions, meat sharing, and territorial boundary patrols. Observations indicate that while maternal kinship affects who cooperates with whom, male chimpanzees nonetheless cooperate quite often and readily with unrelated individuals. Despite these findings, cooperation between wild chimpanzees remains limited in its extent and effects, as males do not appear to cooperate with their paternal relatives ${ }^{58}$ and females do not cooperate as often as males do. Also, cooperation typically is restricted to pairs of individuals and it does not extend beyond members living within the same social group. In contrast, human cooperation involves extensive networks of individuals who assume specialized roles to trade goods and services both within and between groups. As a consequence, it is arguably true that cooperation, with kin and nonkin alike, is a hallmark of humankind, setting us apart in a significant way from our closest living relatives. $^{137}$

Other differences involving cooperation reviewed in this issue ${ }^{138}$ and elsewhere ${ }^{139}$ highlight an additional selective factor that may have played a role in the evolution of humans as a "uniquely unique"140 species. Recent research on female chimpanzee competition should not detract from the fact that female chimpanzees are caring mothers who are extraordinarily attentive to and solicitous of their young. ${ }^{3}$ Offspring care is nonetheless generally restricted to mothers. In this respect, chimpanzees differ sharply from the cooperative breeding systems

\section{Recent studies are beginning to reveal that female chimpanzees compete with each other for space, food, and opportunities to reproduce. Female competition, for the most part, is indirect and manifest in subtle ways...}

displayed by Callitrichid primates and other animals. ${ }^{139}$ This observation has led to the hypothesis that cooperative breeding may have been a singularly important trait leading to the evolution of several unusual aspects of human behavior, life history, and cognition. ${ }^{137-139}$

Similarities as well as differences can be employed to reconstruct the evolution of human behavior. Behavioral similarities among chimpanzees, bonobos, and humans evolve as the result of convergent evolution or common descent. Homologous similarities due to the latter process are of special interest for purposes of behavioral reconstruction. ${ }^{141}$ Homologies shared among chimpanzees, bonobos, and humans are likely to have also been shared by the common ancestor of all three species. From this, it is reasona- ble to assume that early humans possessed these characteristics as well. Although this logic is unquestionable and easy to understand, it is not necessarily easy to apply. Some problems, not always entertained or acknowledged, hinder using information about chimpanzees to make inferences about human behavioral evolution.

One significant problem involves the fact that bonobos are a sister taxon of chimpanzees. Accordingly, data regarding bonobos and chimpanzees are required to determine behaviors that may have been displayed by the last common ancestor. Most attempts to use chimpanzees to reconstruct the evolution of our behavior fail to incorporate bonobos into their analyses. ${ }^{142-147}$ Why this is a problem becomes apparent when considering the potential significance of the extreme intergroup violence that chimpanzees display. Some have interpreted this as supporting the claim that the evolutionary roots of human aggression run deep. ${ }^{148,149}$ Bonobos, however, are much less aggressive than chimpanzees. Clearly, any argument that early humans were extremely aggressive as a consequence of shared ancestry would be on much firmer ground if aggression was practiced on a regular and frequent basis by all three species.

In sum, information about the behavior of chimpanzees continues to inform the study of human behavior and evolution in important ways. Applying this information is sometimes controversial ${ }^{150}$ and presents problems. In addition, a focus on chimpanzees should not take away from the fact that behavioral observations of other animals, primates and nonprimates alike, provide critical comparative data to understand the human condition. Nonetheless, as Huxley ${ }^{151}$ recognized more than 140 years ago, their close evolutionary relationship to us furnishes a strong theoretical rationale for why chimpanzees remain central to our understanding human evolution and behavior.

\section{CONCLUDING COMMENTS}

Nearly 50 years after their inception, studies of the behavior of wild chimpanzees continue to generate widespread attention and interest. Yet despite years 
of dedicated field work by several individuals at sites across the African continent, we still lack answers to fundamental questions. The reason for this is simple. Because of their extremely long life spans and slow reproduction, chimpanzees are slow to give up the secrets of their lives to human observers. As should be clear from the preceding, answering questions regarding male cooperation and female competition will require additional long-term study. But whether such study will be possible remains unclear because chimpanzees are critically endangered throughout Africa. Habitat destruction, ${ }^{152,153}$ a thriving bushmeat trade, ${ }^{152,154}$ and recurrent outbreaks of infectious disease, ${ }^{152,155}$ threaten to drive chimpanzees to extinction. Recent research indicates that populations of chimpanzees in West Africa have suffered a precipitous decline during the past 20 years, ${ }^{156}$ while the famed Kasekela chimpanzee community at Gombe in East Africa continues to face an uncertain fate. ${ }^{157}$ Seven years ago, in an earlier review of chimpanzee behavior for this journal, I concluded by noting the massive void that will be created if we fail to conserve chimpanzees in the wild. Time has passed and it is running out.

\section{ACKNOWLEDGMENTS}

This paper arose as part of a conference organized by the L. S. B. Leakey Foundation to honor two Leakey Prize recipients, Jane Goodall and Toshisada Nishida, for their seminal field research investigating the behavior of wild chimpanzees. I thank the Board of Trustees, the Scientific Executive Committee, and the staff of the Leakey Foundation for inviting me to participate in this conference. John Fleagle solicited this review, and I am especially grateful for his patience during the time this paper was conceived, gestated, and finally written and revised. I also thank John for gently coaxing me to step out on a limb and write about the implications of chimpanzee behavior for the study of human behavior and evolution. John Fleagle, Kristen Hawkes, and three anonymous reviewers furnished helpful comments on the manuscript. My past and ongoing field work in Uganda has been sponsored by the Makerere
University Biological Field Stations, the Uganda Wildlife Authority, and the Uganda National Council for Science and Technology. My field research on chimpanzees has been generously funded by grants from the U. S. National Science Foundation (SBR9253590, BCS-0215622, IOB-0516644), L. S. B. Leakey Foundation, National Geographic Society, Wenner-Gren Foundation for Anthropological Research, University of Michigan, and Detroit Zoological Institute.

\section{REFERENCES}

1 Goodall J. 1963. Feeding behaviour of wild chimpanzees: a preliminary report. Symposium Zool Soc London 10:39-48.

2 Nishida T. 1968. The social group of wild chimpanzees in the Mahale Mountains. Primates 9:167-224.

3 Goodall J. 1986. The chimpanzees of Gombe. Cambridge: Belknap Press.

4 Nishida T. 1990. The chimpanzees of the Mahale Mountains. Tokyo: University of Tokyo Press.

5 Boesch C, Boesch-Achermann H. 2000. The chimpanzees of the Taï Forest. Oxford: Oxford University Press.

6 Sugiyama Y. 2004. Demographic parameters and life history of chimpanzees at Bossou, Guinea. Am J Phys Anthropol 124:154-165.

7 Muller M, Mitani J. 2005. Conflict and cooperation in wild chimpanzees. Adv Stud Behav 35:275-331.

8 Reynolds V. 2005. The chimpanzees of the Budongo Forest. Oxford: Oxford University Press. 9 Darwin C. 1859. On the origin of species by means of natural selection. London: John Murray. p 213.

10 Darwin C. 1871. The descent of man and selection in relation to sex. London: John Murray.

11 West S, Griffin A, Gardner A. 2007. Evolutionary explanations for cooperation. Curr Biol 17:R661-R672.

12 Hamilton W. 1963. The evolution of altruistic behavior. Am Nat 97:354-356.

13 Hamilton W. 1964. The genetical evolution of social behavior. I, II. J Theor Biol 7:1-52.

14 Trivers R. 1971. The evolution of reciprocal altruism. Q Rev Biol 46:189-226.

15 Axelrod R, Hamilton W. 1981. The evolution of cooperation. Science 211:1390-1396.

16 Brown J. 1983. Cooperation: a biologist's dilemma. Adv Study Behav 13:1-37.

17 Dugatkin L. 1997. Cooperation among animals. New York: Oxford University Press.

18 Clutton-Brock T. 2002. Breeding together: kin selection and mutualism in cooperative vertebrates. Science 296:69-72.

19 Sachs J, Mueller U, Wilcox T, Bull J. 2004 The evolution of cooperation. Q Rev Biol 79:135 160.

20 Nowak M. 2006. Five rules for the evolution of cooperation. Science 314:1560-1563.

21 Andersson M. 1994. Sexual selection. Princeton: Princeton University Press.

22 Clutton-Brock T. 2007. Sexual selection in males and females. Science 318:1882-1885.
23 Goodall J. 1968. The behaviour of free-living chimpanzees in the Gombe Stream area. Anim Behav Monographs 1:161-311.

24 Goodall J, Bandora A, Bergmann E, Busse C, Matama H, Mpongo E, Pierce A, Riss D. 1979. Intercommunity interactions in the chimpanzee population of the Gombe National Park. In: Hamburg D, McCown E, editors. The great apes. Menlo Park: Benjamin-Cummings. p 13-54.

25 Nishida T, Hiraiwa-Hasegawa M, Hasegawa T, Takahata Y. 1985. Group extinction and female transfer in wild chimpanzees in the Mahale Mountains National Park, Tanzania. Z Tierpsychol 67:281-301

26 Nishida T, Kawanaka K. 1972. Inter-unitgroup relationships among wild chimpanzees of the Mahale mountains. Kyoto University African Studies 7:131-169.

27 Pusey A. 1979. Intercommunity transfer of chimpanzees in Gombe National Park. In: Hamburg D, McCown E, editors. The great apes. Menlo Park: Benjamin-Cummings. p 465-479.

28 McGrew W, Tutin C. 1978. Evidence for a social custom in chimpanzees? Man 13:234-251.

29 Wrangham R, Nishida T. 1983. Aspilia spp. leaves: a puzzle in the feeding behavior of wild chimpanzees. Primates 24:276-282.

30 Reynolds V, Reynolds F. 1965. Chimpanzees of the Budongo forest. In: DeVore I, editor. Primate behavior. New York: Holt, Rinehart, Winston. p 368-424.

31 Sugiyama Y. 1968. Social organization of chimpanzees in the Budongo Forest, Uganda. Primates 9:225-258.

32 Suzuki A. 1971. Carnivority and cannibalism observed among forest-living chimpanzees. J Anthropol Soc, Nippon 79:30-48.

33 Reynolds V. 1992. Chimpanzees in the Budongo Forest. J Zool 228:695-699.

34 Townsend SW, Slocombe KE, Thompson ME, Zuberbuhler K. 2007. Female-led infanticide in wild chimpanzees. Curr Biol 17:R355-R356.

35 Kortlandt A. 1986. The use of stone tools by wild-living chimpanzees and earliest hominids. J Hum Evol 15:77-132.

36 Sugiyama Y, Koman J. 1979. Social structure and dynamics of wild chimpanzees at Bossou, Guinea. Primates 20:323-339.

37 Matsuzawa T. 2006. Sociocognitive development in chimpanzees: a synthesis of laboratory work and fieldwork. In: Matsuzawa T, Tomonaga $\mathrm{M}$, Tanaka $\mathrm{M}$, editors. Cognitive development in chimpanzees. Tokyo: Springer-Verlag. $p$ 3-33.

38 Ghiglieri M. 1984. The chimpanzees of the Kibale Forest. New York: Columbia University Press.

39 Boesch C. 1978. Nouvelles observations sur les chimpanzes de la foret de Tai (Cote d'Ivoire). Terre et Vie 32:195-201.

40 Wrangham R, Clark A, Isabiryre-Basuta G. 1992. Female social relationships and social organization of Kibale Forest chimpanzees. In: Nishida T, McGrew W, Marler P, Pickford M, deWaal $\mathrm{F}$, editors. Topics in primatology, vol 1. Human origins. Tokyo: Tokyo University Press. p 81-98.

41 Mitani J, Watts D, Muller M. 2002. Recent developments in the study of wild chimpanzee behavior. Evol Anthropol 11:9-25.

42 McGrew W, Baldwin P, Tutin C. 1981. Chimpanzees in a hot, dry and open habitat, Mt. Assirik, Senegal, West Africa. J Hum Evol 10:227244.

43 Pruetz JPB, Bertolani P. 2007. Savanna chimpanzees, Pan troglodytes verus, hunt with tools. Curr Biol 17:412-417. 
44 Sanz C, Morgan D, Gulick S. 2004. New insights into chimpanzees, tools, and termites from the Congo Basin. Am Nat 164:567-581.

45 Pepper J, Mitani J, Watts D. 1999. General gregariousness and specific social preferences among wild chimpanzees. Int J Primatol 20:613 632.

46 Mitani J, Watts D, Pepper J, Merriwether DA 2002. Demographic and social constraints on male chimpanzee behaviour. Anim Behav 64:727737.

47 Gilby I, Wrangham R. 2008. Association patterns among wild chimpanzees (Pan troglodytes schweinfurthii) reflect sex differences in cooperation. Behav Ecol Sociobiol 62:1831-1842.

48 Bauer H. 1979. Agonistic and grooming behavior in the reunion context of Gombe Stream chimpanzees. In: Hamburg D, McCown E, editors. The great apes. Menlo Park: Benjamin-Cummings. p 394-403.

49 Bygott D. 1979. Agonistic behavior, dominance, and social structure in wild chimpanzees of the Gombe National Park. In: Hamburg D, McCown E, editors. The great apes. Menlo Park: Benjamin-Cummings. p 405-427.

50 Nishida T, Corp N, Hamai M, Hasegawa T, Hiraiwa-Hasegawa M, Hosaka K, Hunt K, Itoh N, Kawanaka K, Matsumoto-Oda A, Mitani J, Nakamura M, Norikoshi K, Sakamaki T, Turner L, Uehara S, Zamma, K. 2003. Demography, female life history, and reproductive profiles among the chimpanzees of Mahale. Am J Primatol 59:99-121. 51 Hayaki H, Huffman M, Nishida T. 1989. Dominance among male chimpanzees in the Mahale Mountains National Park, Tanzania. Primates 30:187-197.

52 Newton-Fisher N. 2004. Hierarchy and social status in Budongo chimpanzees. Primates 45:8187.

53 Wroblewski E, Murray C, Keelec B, Schumacher-Stankeya J, Hahn B, Pusey A. 2009. Male dominance rank and reproductive success in chimpanzees, Pan troglodytes schweinfurthii. Anim Behav 77:873-885.

54 Constable J, Ashley M, Goodall J, Pusey A. 2001. Noninvasive paternity assignment in Gombe chimpanzees. Mol Ecol 10:1279-1300.

55 Boesch C, Kohou G, Nene H, Vigilant L. 2006. Male competition and paternity in wild chimpanzees of the Tai forest. Am J Phys Anthropol 130:103-115.

56 Inoue E, Inoue-Murayama M, Vigilant L, Takenaka O, Nishida T. 2008. Relatedness in wild chimpanzees: influence of paternity, male philopatry, and demographic factors. Am J Phys Anthropol 137:256-262.

57 Williams J, Oehlert G, Carlis J, Pusey A. 2004 Why do male chimpanzees defend a group range? Anim Behav 68:523-532.

58 Langergraber K, Mitani J, Vigilant L. 2007. The limited impact of kinship on cooperation in wild chimpanzees. Proc Natl Acad Sci USA 104:7786-7790.

59 Harcourt A, deWaal F. 1992. Coalitions and alliances in humans and other animals. Oxford: Oxford University Press.

60 Riss D, Goodall J. 1977. The recent rise to the alpha rank in a population of free-living chimpanzees. Folia Primatol 27:134-151.

61 deWaal F. 1982. Chimpanzee politics. New York: Harper \& Row.

62 Nishida T. 1983. Alpha status and agonistic alliance in wild chimpanzees (Pan troglodytes schweinfurthii). Primates 24:318-336.

63 Nishida T, Hosaka K. 1996. Coalition strategies among adult male chimpanzees of the
Mahale Mountains, Tanzania. In: McGrew W, Marchant L, Nishida T, editors. Great ape societies. Cambridge: Cambridge University Press. p 114-134.

64 Uehara S, Hiraiwa-Hasegawa M, Hosaka K, Hamai M. 1994. The fate of defeated alpha male chimpanzees in relation to their social networks. Primates 35:49-55.

65 Foster M, Gilby I, Murray C, Johnson A, Wroblewski E, Pusey A. 2009. Alpha male chimpanzee grooming patterns: implications for dominance "style." Am J Primatol 71:136-144.

66 Mitani J, Watts D. 2001. Why do chimpanzees hunt and share meat? Anim Behav 61:915-924.

67 Watts D. 2002. Reciprocity and interchange in the social relationships of wild male chimpanzees. Behaviour 139:343-370.

68 Mitani J. 2006. Reciprocal exchange in chimpanzees and other primates. In: Kappeler P, van Schaik C, editors. Cooperation in primates: mechanisms and evolution. Heidelberg: SpringerVerlag. p 107-119.

69 Duffy K, Wrangham R, Silk J. 2007. Male chimpanzees exchange political support for mating opportunities. Curr Biol 17:R586-R587.

70 Hammerstein P. 2003. Genetic and cultural evolution of cooperation. Cambridge: MIT Press.

71 deWaal F. 1997. The chimpanzee's service economy: food for grooming. Evol Hum Behav 18:375-386.

72 Chapais B. 1995. Alliances as a means of competition in primates: evolutionary, developmental and cognitive aspects. Yearb Phys Anthropol 38:115-136.

73 van Schaik C, Pandit S, Vogel E. 2006 Toward a general model for male-male coalition in primate groups. In: Kappeler P, van Schaik C editors. Cooperation in primates: mechanisms and evolution. Heidelberg: Springer-Verlag. p 151-171.

74 Widdig A, Streich W, Tembrock G. 2000. Coalition formation among male barbary macaques (Macaca sylvanus). Am J Primatol 50:37-51.

75 Silk J, Alberts S, Altmann J. 2004. Patterns of coalition formation by adult female baboons in Amboseli, Kenya. Anim Behav 67:573-582.

76 deWaal F, Harcourt A. 1992. Coalitions and alliances: a history of ethological research. In: Harcourt A, deWaal F, editors. Coalitions and alliances in humans and other animals. Oxford: Oxford University Press. p 1-27.

77 Silk J, Alberts S, Altmann J. 2003. Social bonds of female baboons enhance infant survival. Science 302:1231-1234.

78 Silk J. 2007. Social components of fitness in primate groups. Science 317:1347-1351.

79 Mitani J. 2009. Male chimpanzees form enduring and equitable social bonds. Anim Behav 77:633-640.

80 Cheney D, Seyfarth R. 1990. How monkeys see the world. Chicago: University of Chicago Press.

81 Cheney D, Seyfarth R, 2007. Baboon Metaphysics. Chicago: University of Chicago Press.

82 Teleki G. 1973. The predatory behavior of wild chimpanzees. Lewisburg: Bucknell University Press.

83 Busse C. 1978. Do chimpanzees hunt cooperatively? Am Nat 112:767-770.

84 Boesch C, Boesch H. 1989. Hunting behavior of wild chimpanzees in the Tai National Park. Am J Phys Anthropol 78:547-573.

85 Boesch C. 1994. Chimpanzees-red colobus monkeys: a predator-prey system. Anim Behav 47:1135-1148.

86 Stanford C, Wallis J, Matama H, Goodall J. 1994. Patterns of predation by chimpanzees on red colobus monkeys in Gombe National Park, 1982-1991. Am J Phys Anthropol 94:213-228.

87 Mitani J, Watts D. 1999. Demographic influences on the hunting behavior of chimpanzees. Am J Phys Anthropol 109:439-454.

88 Hosaka K, Nishida T, Hamai M, MatsumotoOda A, Uehara S. 2001. Predation of mammals by the chimpanzees of the Mahale Mountains, Tanzania. In: Galdikas B, Briggs N, Sheeran L, Shapiro G, Goodall J, editors. All apes great and small, vol 1. African apes. New York: Kluwer Academic. p 107-130.

89 Gilby I, Wrangham R. 2007. Risk-prone hunting by chimpanzees (Pan troglodytes schweinfurthii) increases during periods of high diet quality. Behav Ecol Sociobiol 61:1771-1779.

90 Gilby I, Eberly L, Wrangham R. 2008. Economic profitability of social predation among wild chimpanzees: individual variation promotes cooperation. Anim Behav 75:351-360.

91 Yamakoshi G. 1998. Dietary responses to fruit scarcity of wild chimpanzees at Bossou, Guinea: possible implications for ecological importance of tool use. Am J Phys Anthropol 106:283-295.

92 Basabose K, Yamagiwa J. 1997. Predation on mammals by chimpanzees in the montane forest of Kahuzi, Zaire. Primates 38:45-56.

93 Newton-Fisher N, Notman H, Reynolds V. 2002. Hunting of mammalian prey by Budongo Forest chimpanzees. Folia Primatol 73:281-283.

94 Stanford C, Wallis J, Mpongo E, Goodall J. 1994. Hunting decisions in wild chimpanzees. Behaviour 131:1-18.

95 Gilby I. 2006. Meat sharing among the Gombe chimpanzees: harassment and reciprocal exchange. Anim Behav 71:953-963.

96 Gomes C, Boesch C. 2009. Wild chimpanzees exchange meat for sex on a long-term basis. PLoS ONE 4:e5116.

97 Gilby I, Eberly L, Pintea L, Pusey A. 2006. Ecological and social influences on the hunting behaviour of wild chimpanzees, Pan troglodytes schweinfurthii. Anim Behav 72:169-180.

98 Hockings K, Humle T, Anderson J, Biro D Sousa C, Ohasi G, Matsuzawa T. 2007. Chimpanzees share forbidden fruit. PLoS ONE 2:e886.

99 Stumpf R, Boesch C. 2006. The efficacy of female choice in chimpanzees of the Taï Forest, Cote d'Ivoire. Behav Ecol Sociobiol 60:749-765.

100 Muller M, Kahlenberg S, Emery Thompson M, Wrangham R. 2007. Male coercion and the costs of promiscuous mating by female chimpanzees. Proc R Soc London B 274:1009-1014.

101 Nishida T, Hasegawa T, Hayaki H, Takahata Y, Uehara S. 1992. Meat-sharing as a coalition strategy by an alpha male chimpanzee? In: Nishida T, McGrew W, Marler P, Pickford M, deWaal $\mathrm{F}$, editors. Topics in primatology, vol 1 . Human origins. Tokyo: Tokyo University Press. p 159-174.

102 Wrangham R. 1975. Behavioural ecology of chimpanzees in Gombe National Park. Dissertation, University of Cambridge.

103 Blurton-Jones N. 1984. A selfish origin for human food sharing: tolerated theft. Ethol Sociobiol 1:1-3.

104 Whiten A, Goodall J, McGrew WC, Nishida T, Reynolds V, Sugiyama Y, Tutin C, Wrangham R, Boesch C. 1999. Cultures in chimpanzees. Nature 399:682-685.

105 Boesch C, Hohmann G, Marchant L. 2002. Behavioral diversity in chimpanzees and Bonobos. Cambridge: Cambridge University Press.

106 Watts D, Mitani J. 2001. Boundary patrols and intergroup encounters in wild chimpanzees. Behaviour 138:299-327. 
107 Watts D, Mitani J, Sherrow H. 2002. New cases of inter-community infanticide by male chimpanzees at Ngogo, Kibale National Park, Uganda. Primates 43:263-270.

108 Wilson M, Wallauer W, Pusey A. 2004. New cases of intergroup violence among chimpanzees in Gombe National Park, Tanzania. Int J Primatol 25:523-549.

109 Watts D, Muller M, Amsler S, Mbabazi G, Mitani J. 2006. Lethal intergroup aggression by chimpanzees in Kibale National Park, Uganda. Am J Primatol 68:161-180.

110 Boesch C, Head J, Tagg N, Arandjelovic M, Vigilant L, Robbins M. 2007. Fatal chimpanzee attack in Loango National Park, Gabon. Int J Primatol 28:1025-1034

111 Boesch C, Crockford C, Herbinger I, Wittig R, Moebius Y, Normand E. 2008. Intergroup conflicts among chimpanzees in Tai National Park: lethal violence and the female perspective. Am J Primatol 70:519-532.

112 Wilson M, Wrangham R. 2003. Intergroup relations in chimpanzees. Ann Rev Anthropol 32:363-392.

113 Mitani J, Watts D. 2005. Correlates of territorial boundary patrol behaviour in wild chimpanzees. Anim Behav 70:1079-1086.

114 Amsler S. 2009. Ranging behavior and territoriality in chimpanzees at Ngogo, Kibale National Park, Uganda. Dissertation, University of Michigan.

115 Zahavi A. 1975. Mate selection: a selection for a handicap. J Theor Biol 53:205-214.

116 Grafen A. 1990. Biological signals as handicaps. J Theor Biol 144:517-546.

117 Morin P, Moore J, Chakraborty R, Jin L, Goodall J, Woodruff D. 1994. Kin selection, social structure, gene flow, and the evolution of chimpanzees. Science 265:1193-1201.

118 Clutton-Brock T, Parker G. 1995. Punishment in animal societies. Nature 373:209-216.

119 Halperin S. 1979. Temporary association patterns in free ranging chimpanzees: an assessment of individual grouping preferences. In: Hamburg D, McCown E, editors. The great apes. Menlo Park: Benjamin-Cummings. p 491499.

120 Wrangham R, Smuts B. 1980. Sex differences in the behavioral ecology of chimpanzees in the Gombe National Park, Tanzania. J Reprod Fertil 28:13-31.

121 Williams J, Pusey A, Carlis J, Farm B, Goodall J. 2002. Female competition and male territorial behaviour influence female chimpanzee's ranging patterns. Anim Behav 63:347-360.

122 Wakefield M. 2008. Grouping patterns and competition among female Pan troglodytes schweinfurthii at Ngogo, Kibale National Park, Uganda. Int J Primatol 29:907-929.

123 Nishida T. 1989. Social interactions between resident and immigrant female chimpanzees. In: Heltne P, Marquardt L, editors. Understanding chimpanzees. Cambridge: Harvard University Press. p 68-89.

124 Wittig R, Boesch C. 2003. Food competition and linear dominance hierarchy among female chimpanzees of the Tai National Park. Int J Primatol 24:847-867.

125 Murray C, Eberly L, Pusey A. 2006. Foraging strategies as a function of season and rank among wild female chimpanzees (Pan troglodytes). Behav Ecol 17:1020-1028.

126 Murray C, Mane S, Pusey A. 2007. Dominance rank influences female space use in wild chimpanzees, Pan troglodytes: towards an ideal despotic distribution. Anim Behav 74:1795-1804. 127 Kahlenberg S, Thompson M, Muller M Wrangham R. 2008. Immigration costs for female chimpanzees and male protection as an imigrant counterstrategy to intrasexual aggression. Anim Behav 76:1497-1509.

128 Kahlenberg S, Thompson M, Wrangham R. 2008. Female competition over core areas in Pan troglodytes schweinfurthii, Kibale National Park, Uganda. Int J Primatol 29:931-947.

129 Trivers R. 1972. Parental investment and sexual selection. In: Campbell B, editor. Sexual selection and the descent of man. Chicago: Aldine de Gruyter. p 136-179.

130 Wrangham R, Conklin-Brittain N, Hunt K. 1998. Dietary response to chimpanzees and cercopithecines to seasonal variation in fruit abundance. I. Antifeedants. Int J Primatol 19:949-970.

131 Langergraber K, Mitani J, Vigilant L. 2009. Kinship and social bonds in female chimpanzees (Pan troglodytes). Am J Primatol 71:840-851.

132 Pusey A, Murray C, Wallauer W, Wilson M, Wroblewski E, Goodall J. 2008. Severe aggression among female Pan troglodytes schweinfurthii at Gombe National Park, Tanzania. Int J Primato 29:949-973.

133 Thompson M, Kahlenberg S, Gilby I, Wrang ham R. 2007. Core area quality is associated with variance in reproductive success among female chimpanzees at Kibale National Park. Anim Behav 73:501-512.

134 Pusey A, Oehlert G, Williams J, Goodall J. 2005. Influence of ecological and social factors on body mass of wild chimpanzees. Int $\mathbf{J}$ Primato 26:3-31.

135 Pusey A, Williams J, Goodall J. 1997. The influence of dominance rank on the reproductive success of female chimpanzees. Science 277:828 831.

136 Lehmann J, Boesch C. 2009. Sociality of the dispersing sex: the nature of social bonds in West African female chimpanzees, Pan troglodytes. Anim Behav 77:377-387.

137 Hill K, Barton M, Hurtado M. 2009. The emergence of human uniqueness: characters underlying behavioral modernity. Evol Anthropol 18:174-187.

138 Burkart J, Hrdy S, van Schaik C. 2009. Cooperative breeding and human cognitive evolution. Evolutionary Anthropology 18:188-199.

139 Hrdy S. 2009. Mothers and others: the evolutionary origins of mutual understanding. Cambridge: Belknap Press.

140 Alexander R. 1990. How did humans evolve? Reflections on the uniquely unique species. University of Michigan Museum of Zoology Special Publication 1:1-38.
141 Mitani J. n.d. Chimpanzee models of human behavioral evolution. In: Sponheimer M, Reed K, Lee-Thorp J, Ungar P, editors. Early hominin paleoecology. Boulder, CO: University Press of Colorado.

142 Goodall J, Hamburg D. 1975. Chimpanzee behavior as a model for the behavior of early man: new evidence of possible origins of human behavior. Am Handb Psychol 6:14-43.

143 McGrew W. 1981. The female chimpanzee as a human evolutionary prototype. In: Dahlberg F, editor. Woman the gatherer. New Haven: Yale University Press. p 35-73.

144 Ghiglieri M. 1987. Sociobiology of the great apes and the hominid ancestor. J Hum Evol 16:319-357.

145 Wrangham R. 1987. The significance of African apes for reconstructing human social evolution. In: Kinzey W, editor. The evolution of human behavior: primate models. Albany: State University of New York Press. p 51-71.

146 Foley R. 1989. The evolution of hominid social behaviour. In: Standen V, Foley R, editors. Comparative socioecology: the behavioural ecology of humans and other mammals. Oxford: Blackwell Scientific. p 473-494.

147 Stanford C. 1999. The hunting apes: meat eating and the origins of human behavior. Princeton: Princeton University Press.

148 Wrangham R. 1999. The evolution of coalitionary killing. Yearb Phys Anthropol 42:1-30.

149 Wrangham R, Peterson D. 1996. Demonic males: apes and the origins of human violence. New York: Houghton Mifflin.

150 Sayers K, Lovejoy O. 2008. The chimpanzee has no clothes: a critical examination of Pan troglodytes in models of human evolution. Curr Anthropol 49:87-114.

151 Huxley T. 1863. Evidence as to man's place in nature. New York: D. Appleton.

152 Walsh P, Abernethy K, Bermejo M, Beyersk R, De Wachter P, Akou M, Huljbregis B, Mambounga D, Toham A, Kilbourn A, Lahm S, Latour S, Maisels F, Mbina C, Mihindou Y, Obiang S Effa E, Starkey, M, Telfer P, Thibault M, Tutin C, White L, Wilkie D. 2003. Catastrophic ape decline in western equatorial Africa. Nature 422:611-614. 153 Laporte N, Stabach J, Grosch R, Lin T, Goetz S. 2007. Expansion of industrial logging in Central Africa. Science 316:1451.

154 Brashares J, Arcese P, Sam M, Coppolillo P, Sinclair A. Balmford A. 2004. Bushmeat hunting, wildlife declines, and fish supply in West Africa. Science 306:1180-1183.

155 Leroy E, Rouquet P, Formenty P, Souquiere S, Kilbourne A, Froment J, Bermejo M, Smit S, Karesh W, Swanepoel R, Zaki S, Rollin, P. 2004. Multiple Ebola virus transmission events and rapid decline of central African wildlife. Science 303:387-390.

156 Campbell G, Kuehl H, Kouame P, Boesch C. 2008. Alarming decline of West African chimpanzees in Cote d'Ivoire. Curr Biol 18:R903-R904.

157 Pusey A, Wilson M, Collins DA. 2008. Human impacts, disease risk, and population dynamics in the chimpanzees of Gombe National Park, Tanzania. Am J Primatol 70:738-744.

(C)2009 Wiley-Liss, Inc.
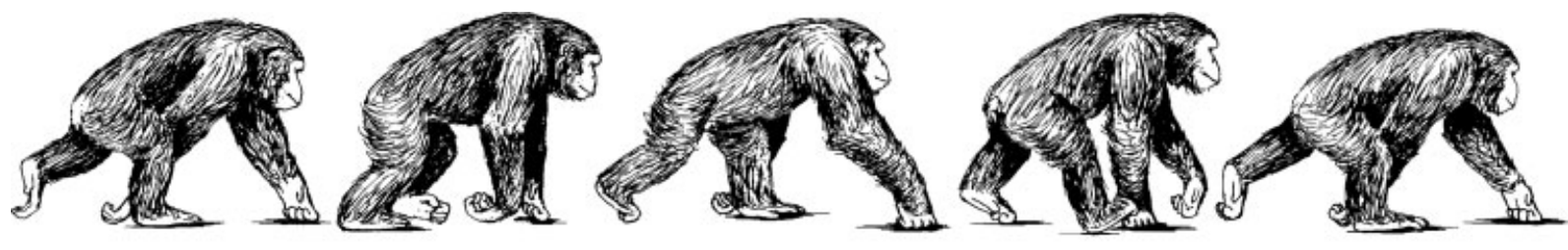